\title{
Neutrophil-to-Lymphocyte Ratio and Platelet-to- Lymphocyte Ratio Alone or Combined with Prostate- Specific Antigen for the Diagnosis of Clinically Significant Prostate Cancer
}

Research Article

Keywords:

Posted Date: December 14th, 2020

DOI: https://doi.org/10.21203/rs.3.rs-100942/v2

License: (1) This work is licensed under a Creative Commons Attribution 4.0 International License. Read Full License 


\section{Abstract}

The authors have requested that this preprint be withdrawn due to author disagreement.

\section{Full Text}

The authors have withdrawn this preprint from Research Square. 